\title{
Translocation of BBAP from the cytoplasm to the nucleus reduces the metastatic ability of vemurafenib-resistant SKMEL28 cells
}

\author{
NGUYEN DINH THANG ${ }^{1,2}$, NGUYEN VAN MINH ${ }^{2}$ and PHAM THU HUONG ${ }^{2}$ \\ ${ }^{1}$ Department of Biochemistry and Plant Physiology, Faculty of Biology; \\ ${ }^{2}$ Key Laboratory of Enzyme and Protein Technology, VNU University of Science, \\ Vietnam National University, Hanoi 120564, Vietnam
}

Received October 25, 2015; Accepted November 1, 2016

DOI: $10.3892 / \mathrm{mmr} .2016 .5976$

\begin{abstract}
To the best of our knowledge, the present study is the first to demonstrate that treatment of vemurafenib-resistant SKMEL28 (SKMEL28-R) cells with paclitaxel leads to a shift in localization of the E3-ligase BBAP from the cytoplasm to the nucleus, consequently decreasing the metastatic ability of this cell line. The present study revealed that the movement of BBAP from the cytoplasm to nucleus initiated a change in cell morphology. In addition, the translocation of BBAP led to a decrease of metastatic characteristics in SKMEL28-R cells, including migration and invasion via downregulation of the phosphorylated form of focal adhesion kinase and $\mathrm{N}$-cadherin, as well as an upregulation of p21 and E-cadherin. The results of the present study suggested that BBAP may not only be a novel biomarker for melanoma, but also a novel therapeutic target for treatment of metastatic melanoma.
\end{abstract}

\section{Introduction}

BBAP is an E3 ubiquitin ligase protein and is a member of the Deltex family. The total protein is 740 amino acids in length, containing, two potential nuclear localization signals (amino acids 20-26 and 462-478), a possible nuclear export signal (amino acids 325-334), a classic RING finger domain (amino acids 561-599) and a C-terminus (amino acids 555-740), and is highly homologous to the conserved C-termini of other Deltex family members. BBAP was originally identified as a binding partner of the B-aggressive lymphoma 1 (BAL1) protein, present in diffuse large B-cell lymphoma $(1,2)$. BBAP has been previously revealed as being highly expressed in the thymus of mice (3). BBAP expression has also been detected in the

Correspondence to: Dr Nguyen Dinh Thang, Department of Biochemistry and Plant Physiology, Faculty of Biology, VNU University of Science, Vietnam National University, 334 Nguyen Trai Street, Thanh Xuan, Hanoi 120564, Vietnam

E-mail: ndthang@hus.edu.vn

Key words: melanoma, $B R A F^{\mathrm{v} 600 \mathrm{E}}$, vemurafenib, paclitaxel, cancer treatment telencephalic vesicles, hypothalamus, anterior pituitary, olfactory bulb, nasal cavity, mouth cavity, urogenital sinus, midgut loops and rectum (3). Histone $\mathrm{H} 4$ undergoes monoubiquitylation by BBAP and selectively modulates the DNA damage response. In addition, the increased expression of BBAP in lymphoma is resistant to DNA-damaging chemotherapeutic agents (4). Previous reports have demonstrated the functions of BBAP in the development of melanoma and lymphoma $(2,5)$.

Metastasis of a primary tumor to a secondary site is the major cause of mortality from solid tumor types (4-6). The progression to metastasis involves a series of discrete steps, commonly known as the metastatic cascade. Tumor cells must first invade the primary tumor, dissociate from the tumor mass and be transported to nearby or distant secondary sites in the cascade (4). Invasion is a hallmark for the malignancy of cancer cells.

$\mathrm{N}$-cadherin serves a pivotal role in promoting metastasis through differential regulation of extracellular signal-regulated kinases. $\mathrm{N}$-cadherin-dependent adhesion impairs the upregulation of the two cyclin-dependent kinase inhibitors, p21 and p27 $(7,8)$. Ectopic expression of N-cadherin increases tumor cell motility, leading to cadherin switching in the regulation of cell behavior $(9,10)$. In addition, a direct relationship between $\mathrm{N}$-cadherin and E-cadherin exists, whereby downregulation of E-cadherin is negatively correlated with upregulation of $\mathrm{N}$-cadherin (11-14). p21 (WAF1/CIP1) serves an important role in controlling cell cycle arrest by regulating the activity of cyclins and cyclin-dependent kinases (15-18). p21 is able to inhibit cell growth through cell cycle arrest of skin cancer cells, including melanoma (7,19-21).

Previous reports have demonstrated that localization sites of certain molecules define their roles and regulate the development of cancer (22-24). Our previous study indicated that $B R A F^{\mathrm{V} 600 \mathrm{E}}$-harboring melanoma cell lines were resistant to the B-Raf enzyme inhibitor, vemurafenib, through various mechanisms (25). It has also been revealed that treatment of vemurafenib-resistant SKMEL28 cells (SKMEL28-R) with paclitaxel decreased the metastatic characteristics of the cells via downregulation of the epidermal growth factor receptor/AKT pathway. Furthermore, a previous study demonstrated that BBAP may serve an important role in melanoma development and progression (5); however, previous studies have demonstrated that BBAP predominantly exists in the 
cytoplasm of the cells $(1,2)$. In the present study, the role of BBAP in melanoma in vitro was investigated when it was translocated from the cytoplasm to the nucleus of SKMEL28-R cells.

\section{Materials and methods}

Cell culture. SKMEL-28 cells were purchased from American Type Culture Collection (Manassas, VA, USA). An SKMEL28-R cell line was established, as previously described (25). SKMEL28-R cells were cultured in RPMI-1640 medium supplemented with $10 \%$ fetal bovine serum (FBS; Gibco; Thermo Fisher Scientific, Inc., Waltham, MA, USA) and $1 \%$ penicillin/streptomycin (Thermo Fisher Scientific, Inc., Waltham, $\mathrm{MA}, \mathrm{USA}$ ) at $37^{\circ} \mathrm{C}$ in $5 \% \mathrm{CO}_{2}$.

Immunocytochemistry. Immunocytochemistry was performed to investigate the protein expression of molecules, according to a previous study (25). SKMEL28-R cells were fixed with $1 \%$ paraformaldehyde and blocked with $5 \%$ FBS for $30 \mathrm{~min}$ at room temperature. The cells were subsequently stained with $10 \mu \mathrm{g} / \mathrm{ml}$ rabbit anti-BBAP antibody (cat. no. A300-833; Bethyl Laboratories, Inc., Montegomery, USA; 1:50) conjugated with Alexa Fluor ${ }^{\circledR} 594$ (Thermo Fisher Scientific, Inc.) with ratio $1 / 3$ of anti-BBAP antibody/Alexa Fluor ${ }^{\circledR} 594$ at room temperature for $3 \mathrm{~h}$ in the dark. The nuclei were counterstained with DAPI (blue). Images were captured with a x40 objective.

Immunoblotting. Immunoblotting was performed to investigate protein, as previously described (25). The cells were washed twice with ice-cold phosphate-buffered saline and lysed in $0.3 \mathrm{ml}$ lysis buffer containing HEPES (20 mM, pH 7.4), $\mathrm{NaCl}$ (150 mM), b-glycerophosphate (12.5 mM), $\mathrm{MgCl}_{2}(1.5 \mathrm{mM})$, EDTA (2 mM), NaF (10 mM), DTT (2 mM), $\mathrm{Na}_{3} \mathrm{VO}_{4}(1 \mathrm{mM})$, phenylmethylsulfonyl fluoride $(1 \mathrm{mM})$, aprotinin $(20 \mathrm{mM})$ and Triton X-100 (0.5\%). Whole cell lysates were resolved by SDS-PAGE and transferred onto Hybond-P membranes (GE Healthcare Life Sciences, Chalfont, UK). The membranes were incubated with the following various antibodies: Rabbit polyclonal anti-BBAP (cat. no. A300-833; Bethyl Laboratories Inc., Montegomery, USA), rabbit polyclonal anti-phosphorylated FAK (tyrosine 397; cat. no. 44-624G; Invitrogen; Thermo Fisher Scientific, Inc.), mouse monoclonal anti-E-cadherin (cat. no. 610181; BD Biosciences, Franklin Lakes, NJ, USA), mouse monoclonal anti- $\alpha$-FAK (cat. no. 05-537; Merck-Millipore, Darmstadt, Germany), mouse monoclonal anti-N-cadherin (cat. no. 610921; BD Biosciences) and goat polyclonal anti-p21 (WAF1/CIP1; cat. no. sc-397G; Santa Cruz Biotechnology, Inc), all used at 1:1,000. Following incubation with primary antibody, the membranes were probed with horseradish peroxidase-conjugated antibodies against goat anti-rabbit (cat. no. A16110; Invitrogen; Thermo Fisher Scientific, Inc.), goat anti-mouse IgG (cat. no. 31430; Invitrogen; Thermo Fisher Scientific, Inc.), donkey anti-goat IgG (cat. no. 31402; Invitrogen; Thermo Fisher Scientific, Inc.) or goat anti-mouse IgG (cat. no. 12-3491 Merck-Millipore, Darmstadt, Germany) with dilution rates of 1:5,000. The proteins were visualized using an Enhanced Chemiluminescence Western Blotting system or ECL Advance (GE Healthcare Life Sciences). Mouse monoclonal anti- $\beta$-tubulin antibody (cat. no. T4026;
Sigma-Aldrich, St. Louis, MO, USA; 1:2,000) was used as a loading control for the immunoblotting.

Scratch wound healing assay. Cell wound healing was performed, as described previously (25). Six-well plates (BD Biosciences, Franklin Lakes, NJ, USA) were incubated overnight in $1 \mathrm{ml}$ RPMI-1640 medium, containing $40 \mu \mathrm{g} / \mathrm{ml}$ collagen. The cells were grown to $100 \%$ confluence on the collagen-coated plates in RPMI-1640 medium supplemented with $10 \%$ FBS. Scratch wounds were created in confluent monolayers using a sterile p200 pipette tip. A total of four perpendicular semi-opaque marks were placed across each scratch on the external surface of the well to standardize quantitative analysis. Following washing, the suspended cells were washed three times, and the wounded monolayers were again cultured in RPMI-1640 medium. Following incubation for 12 and $24 \mathrm{~h}$, repopulation of the wounded areas was observed under phase-contrast microscopy (Olympus Corporation, Tokyo, Japan). Using the NIH ImageJ image-processing program (National Institutes of Health, Bethesda, MD, USA), the size of the scratch wound area was determined at each time point from the digital images.

Invasion assay. Cell invasion ability was evaluated using an invasion assay, according to a previous study (5). A total of $2 \times 10^{5}$ cells in either $300 \mu \mathrm{l}$ normal culture medium (10\% FBS) or starving culture medium $(0.5 \% \mathrm{FBS})$ were applied to a matrigel-coated upper chamber ( $8 \mu \mathrm{m}$ in pore size). The upper chambers were subsequently placed in 24-well culture plates containing $600 \mu \mathrm{l}$ conditioned medium with $0.5 \%$ FBS to trigger invasion activity and were incubated for $12 \mathrm{~h}$. Invading cells were stained with hematoxylin/eosin and counted under a microscope.

Statistical analysis. Statistical analysis in was performed according to a previous study (5). Results from three independent experiments in each group were statistically analyzed by Student's $t$-test. The data are presented as the mean \pm standard deviation. SPSS (version 18.0) software package (SPSS, Inc., Chicago, IL, USA) was used for statistical analysis, $\mathrm{P}<0.05$ was considered to indicate a statistically significant difference.

\section{Results}

Translocation of BBAP causes morphological changes of SKMEL28-R cells. SKMEL28-R cells were treated with $100 \mathrm{nM}$ paclitaxel. Notably, treatment with paclitaxel resulted in presentation of several colonies with abnormal morphology consisting of elongated and dendritic shapes, compared with the oval shapes of control cell populations (Fig. 1A and B). These colonies were isolated and cultured for further experiments. The role of BBAP in melanoma development and progression was previously established (5). Therefore, the present study examined the expression levels and localizations of BBAP in untreated and paclitaxel-treated SKMEL28-R cells. Of note, although the total expression level of BBAP was almost unchanged in paclitaxel-treated SKMEL-28R cells (Fig. 1C, lane 1) compared with that in the untreated SKMEL-28R (Fig. 1C, lane 2), localization of BBAP was shifted from the cytoplasm in untreated cells (Fig. 1B) to the 
$\mathbf{A}$
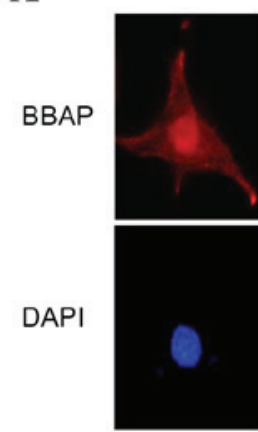

merged
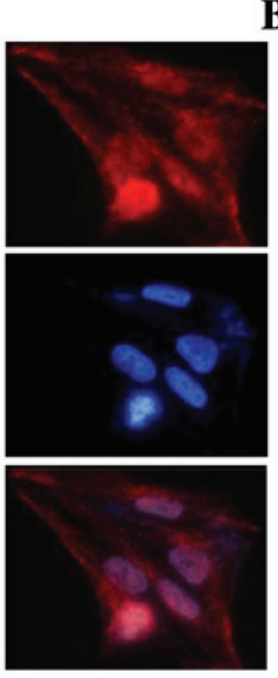

B

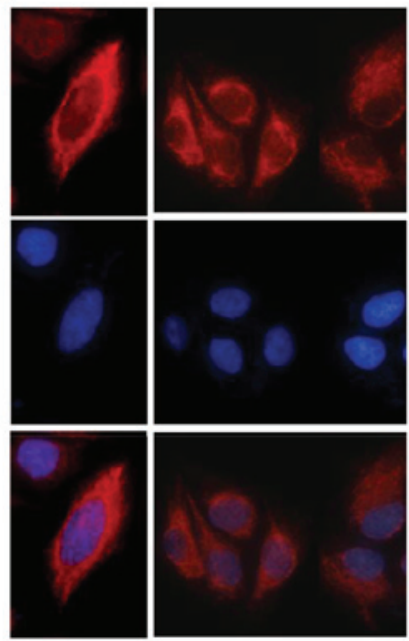

C

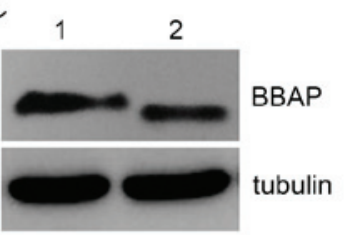

Figure 1. Localization sites and expression levels of BBAP in SKMEL28-R cells. BBAP localizes to the nucleus of (A) paclitaxel-treated SKMEL28-R cells and the cytoplasm of (B) untreated SKMEL28-R cells. (C) The total protein expressions of BBAP in paclitaxel-treated SKMEL-28R cells (lane 1) and in untreated SKMEL-28R cells (lane 2) were measured by immunoblotting. Tubulin was used as an internal control.

A

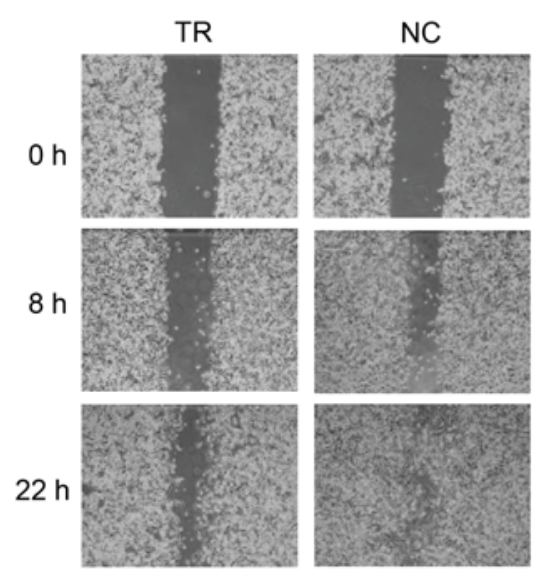

B

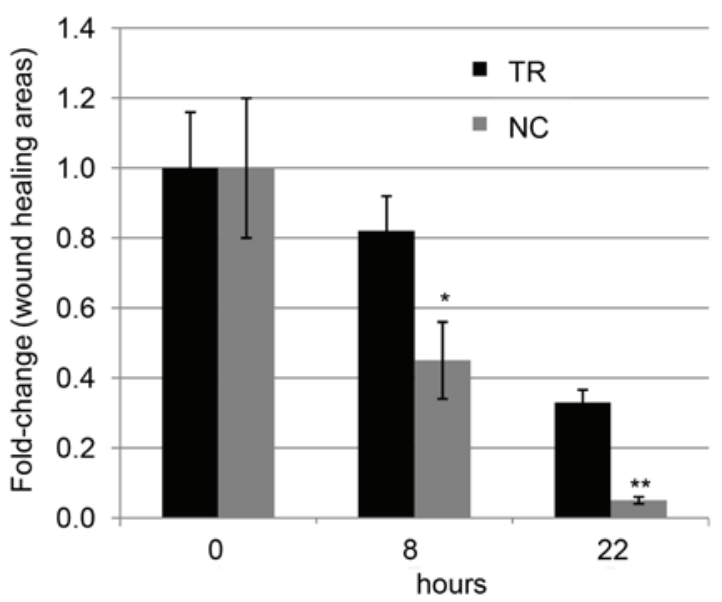

Figure 2. Effect of localization sites of BBAP on migration in SKMEL28-R cells. The migratory ability of SKMEL28-R cells was evaluated using a scratch wound healing assay. Wound areas healed by untreated SKMEL28-R cells and treated SKMEL28-R cells are presented as (A) images and (B) fold-change. The data are presented as the mean \pm standard deviation $\left({ }^{*} \mathrm{P}<0.05\right.$ and ${ }^{* *} \mathrm{P}<0.01$ compared with the NC group, as determined by Student's $t$-test. NC, negative control; TR, treatment group.

nucleus in paclitaxel-treated cells (Fig. 1A). This movement resulted in the expression level of BBAP changing in the cytoplasm and nucleus of treated cells compared with that in untreated cells. The immunohistochemistry results using anti-BBAP antibodies demonstrated that the expression of BBAP in cytoplasm of untreated cells (Fig. 1B) was increased compared with that of the treated cells (Fig. 1A). Conversely, the expression of BBAP in the nucleus of untreated cells (Fig. 1B) was decreased compared with that of the treated cells (Fig. 1B).

Localization of BBAP in the nucleus decreases metastatic ability of SKMEL28-R cells. Scratch would healing and invasion assays were performed to investigate the metastatic and invasive ability of the SKMEL28-R cell line.
Paclitaxel-treated SKMEL28-R and untreated SKMEL28-R cells were pre-cultured in starving conditions (0.5\% FBS) for $8 \mathrm{~h}$ prior to use in both assays. The results demonstrated that untreated SKMEL28-R cells had 2.2- and 4.1-fold higher metastatic abilities, respectively, in scratch would healing (Fig. 2) and invasion (Fig. 3) assays when compared with treated SKMEL28-R cells. This suggested that the metastatic ability of SKMEL28-R cell line may be associated with localization sites of BBAP.

Localization of BBAP in the nucleus downregulates the expression levels of $N$-cadherin and $p F A K$, and upregulates the expression levels of E-cadherin and $p 21$ in SKMEL28-R cells. Western blotting was used to examine the expression levels of BBAP and other molecules associated with metastatic 
A

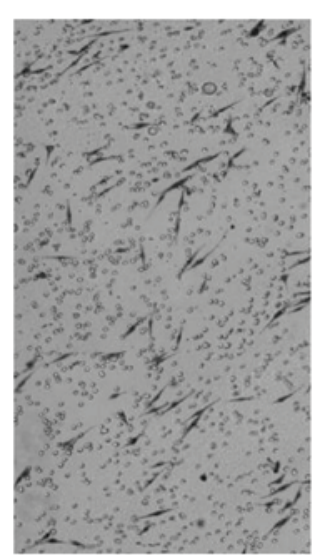

TR

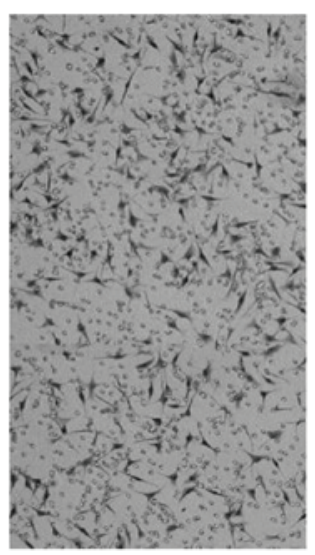

NC
B

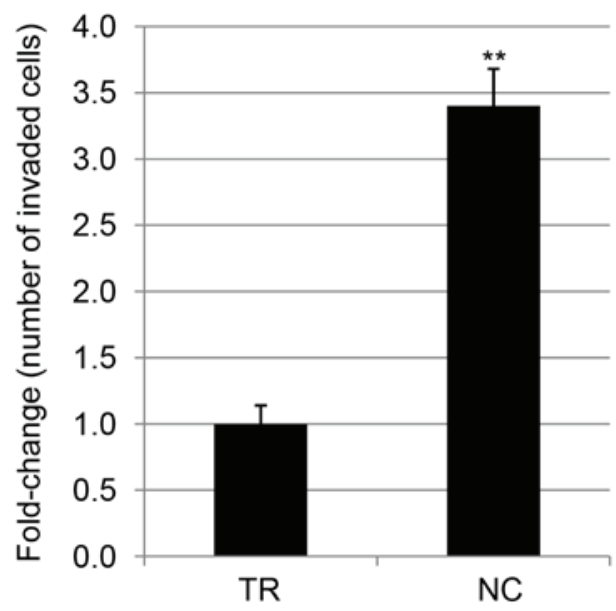

Figure 3. Effect of BBAP localization sites on the invasion of SKMEL28-R cells. The invasive ability of SKMEL28-R cells was evaluated using an invasion assay. The number of invading untreated SKMEL28-R cells and treated SKMEL28-R cells are presented as (A) images and (B) the fold-change. The data are presented as the mean \pm standard deviation ( ${ }^{* *} \mathrm{P}<0.01$ compared with the NC group, as determined by Student's $t$-test). NC, negative control; TR, treatment group.

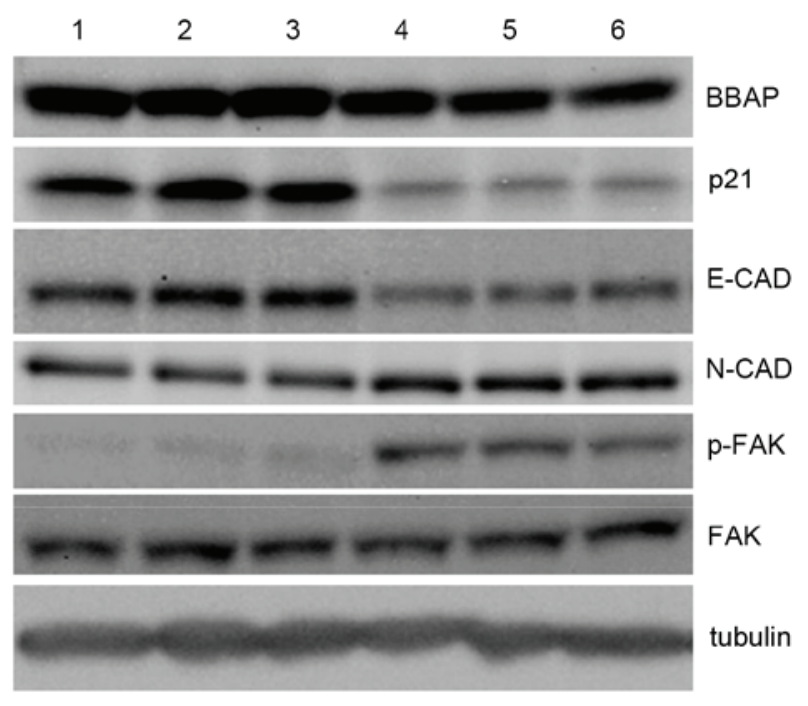

Figure 4. Protein expression levels in SKMEL28-R cells. Protein and phosphorylation levels of BBAP, p21, E-CAD, N-CAD, p-FAK and FAK in paclitaxel-treated SKMEL28-R cells (lanes 1-3) and untreated SKMEL28-R cells (lanes 4-6) were measured by immunoblotting. Tubulin was used as an internal control. E-CAD, E-cadherin; N-CAD, N-cadherin; p-, phosphorylated; FAK, focal adhesion kinase.

ability, including N-cadherin, E-cadherin, FAK, phosphorylated (p-)FAK and p21 in untreated and paclitaxel-treated SKMEL28-R cells (Fig. 4). The results revealed that while the expression levels of BBAP were marginally decreased, the expression levels of $\mathrm{N}$-cadherin and $\mathrm{p}$-FAK in treated cells (Fig. 4, lanes 1-3) were markedly decreased compared with those in the untreated cells (Fig. 4, lanes 4-6). In addition, the expression levels of E-cadherin and p21 were higher in treated cells (Fig. 4, lanes 1-3) compared with those in the untreated cells (Fig. 4, lanes 4-6). These results suggested that BBAP localization to the nucleus downregulated the expression of several molecules, which, in turn, reduced the metastatic ability of the cells.

\section{Discussion}

Previous studies identified that the expression of BBAP in skin tissue, normal epithelial cells and fibroblasts is low $(3,26)$. Our previous study identified that SKMEL-28 cells expressed BBAP more highly compared with that of other melanoma cell lines (5); therefore the present study examined this particular cell line to further investigate the role of BBAP, since expression levels may be associated with the development of melanoma (5). This is the first study, to the best of our knowledge, to indicate that the localization site of the BBAP may contribute to its role in regulating the metastatic activities of SKMEL28-R cells. The results of the in vitro scratch wound healing and invasion assays demonstrated that migration and invasion abilities were decreased in paclitaxel-treated SKMEL28-R cells compared with those of untreated SKMEL28-R cells. The process of metastasis has been recorded as follows: Cell invasion of the primary solid tumor, dissociation from the tumor mass and transportation to nearby or distant secondary sites (4). Various signaling molecules have been reported to control the process. In the present study, it was revealed that the translocation of BBAP from the cytoplasm to the nucleus led to the downregulation of N-cadherin and p-FAK, which acted as cancer-promoting molecules, and upregulation of E-cadherin and p21, which were reported as cancer-inhibiting molecules (7-14).

Currently, few studies have investigated the role of BBAP in the development of leukemia $(1,3,4,26-29)$. In addition, a limited number of publications examine the association between BBAP and solid tumor cancer types, including melanoma. Bachmann et al (29) demonstrated that BBAP regulated IRF-1 via STAT1 signaling and consequently affected metastasis in prostate cancer. The inhibition of BBAP resulted in decreased metastasis in prostate cancer cells (30). The association and interactions between STAT1 and FAK and/or N-cadherin and/or p21 have been previously well-established (30-36). 
Paclitaxel has been reported as a drug that regulates the development of cancer via promotion of the expression of p21 (37-38) and E-cadherin (39), and inhibition of FAK expression in certain type of cancer cells (40). However, the molecular mechanism of this process remains unclear. The present study is the first, to the best of our knowledge, to demonstrate that treatment with paclitaxel leads to morphological changes of cancer cells via translocation of BBAP and consequent upregulation of p21 and E-cadherin, and downregulation of $\mathrm{N}$-cadherin and p-FAK. The results suggested that BBAP may be a novel molecule that can significantly contribute in the paclitaxel-mediated FAK/STAT1/p21 signaling pathway. In another recently published study, retardation of DNA damage and enhanced cellular viability was dependent on the localization of the BAL1-BBAP complex (27). This may further support the importance of BBAP localization in cancer development.

Previous studies have exhibited that vemurafenib had potential to decrease the potential for metastasis of $B R A F^{\mathrm{V} 600 \mathrm{E}}$-carrying melanoma via the inhibition of p-AKT $(41,42)$. As a result, the Food and Drug Administration approved vemurafenib for clinical application to treat metastatic melanoma (43). Unfortunately, the drug is only effective to inhibit melanoma for $\sim 1$ year. The resistance of the melanoma to vemurafenib is caused by the reactivation of p-AKT (44). Based on the present results, the current study involved production of a vemurafenib-resistant SKMEL-28 (named SKMEL-28R) cell line for further studies, with the hope that the combination treatment of vemurafenib and other novel approaches will boost the effectiveness on $B R A F^{\mathrm{V} 600 \mathrm{E}}$-harboring melanomas. This preliminary study focuses only on SKMEL-28R cell line, and therefore, one finite conclusion cannot be drawn for other cancer cells. Therefore further experiments are necessary to examine the localization sites of BBAP and cellular metastasis in various melanoma cells that highly express BBAP.

Taken together, the present results suggested that localization of BBAP to the nucleus of the cells may reduce the metastatic abilities of cells via the inhibition of $\mathrm{N}$-cadherin and p-FAK, and activation of E-cadherin and p21 molecules. In conclusion, the analysis of BBAP demonstrated not only a role as a potential biomarker, but also a role as a potential therapeutic target in melanoma.

\section{Acknowledgements}

The present study was funded by the Vietnam National Foundation for Science and Technology Development (no. 106-NN.02-2013.07).

\section{References}

1. Aguiar RC, Yakushijin Y, Kharbanda S, Salgia R, Fletcher JA and Shipp MA: BAL is a novel risk-related gene in diffuse large B-cell lymphomas that enhances cellular migration. Blood 96: 4328-4334, 2000.

2. Takeyama K, Aguiar RC, Gu L, He C, Freeman GJ, Kutok JL, Aster JC and Shipp MA: The BAL-binding protein BBAP and related Deltex family members exhibit ubiquitin-protein isopeptide ligase activity. J Biol Chem 278: 21930-21937, 2003.

3. Hakmé A, Huber A, Dolle P and Schreiber V: The macroPARP Genes Parp-9 and Parp-14 are developmentally and differentially regulated in mouse tissues. Dev Dyn 237: 209-215, 2008
4. Yan Q, Dutt S, Xu R, Graves K, Juszczynski P, Manis JP and Shipp MA: BBAP monoubiquitylates Histone $\mathrm{H} 4$ at Lysine 91 and Selectively modulates the DNA damage response. Mol Cell 36: 110-120, 2009.

5. Thang ND, Yajima I, Kumasaka MY, Iida M, Suzuki T and Kato M: Deltex-3-like (DTX3L) stimulates metastasis of melanoma through FAK/PI3K/AKT but not MEK/ERK pathway. Oncotarget 6: 14290-14299, 2015.

6. Gupta GP and Massagué J: Cancer metastasis: Building a framework. Cell 127: 679-695, 2006.

7. Zhang Y, Sturgis EM, Zafereo ME, Wei Q and Li G: p14ARF genetic polymorphisms and susceptibility to second primary malignancy in patients with index squamous cell carcinoma of the head and neck. Cancer 117: 1227-1235, 2011.

8. Cheng TH, Hsu PK, Li AF, Hung IC, Huang MH and Hsu HS: Correlation of p53, MDM2 and p14(ARF) protein expression in human esophageal squamous cell carcinoma. J Cancer Res Clin Oncol 135: 1577-1582, 2009.

9. Lin TH, Kuo HC, Chou HP and Lu FJ: Berberine enhances inhibition of glioma tumor cell migration and invasiveness mediated by arsenic trioxide. BMC Cancer 8: 58, 2008.

10. Hsia DA, Mitra SK, Hauck CR, Streblow DN, Nelson JA, Ilic D, Huang S, Li E, Nemerow GR, Leng J, et al: Differential regulation of cell motility and invasion by FAK. J Cell Biol 160: 753-767, 2003.

11. Aplin AE, Howe AK and Juliano RL: Cell adhesion molecules, signal transduction and cell growth. Curr Opin Cell Biol 11: 737-744, 1999.

12. Johnson JP: Cell adhesion molecules in the development and progression of malignant melanoma. Cancer Metastasis Rev 18: 345-357, 1999.

13. Hazan RB, Phillips GR, Qiao RF, Norton L and Aaronson SA: Exogenous expression of $\mathrm{N}$-cadherin in breast cancer cell induces cell migration, invasion, and metastasis. J Cell Biol 148: 779-790, 2000

14. Derycke LD and Bracke ME: N-cadherin in the spotlight of cell-cell adhesion, differentiation, embryogenesis, invasion and signaling. Int J Dev Biol 48: 463-476, 2004.

15. Bottazzi ME, Zhu X, Böhmer RM and Assoian RK: Regulation of p21(cip1) expression by growth factors and the extracellular matrix reveals a role for transient ERK activity in G1 phase. J Cell Biol 146: 1255-1264, 1999.

16. Roovers $\mathrm{K}$ and Assoian RK: Integrating the MAP kinase signal into the G1 phase cell cycle machinery. Bioessays 22: 818-826, 2000.

17. Sherr CJ and Roberts JM: Inhibitors of mammalian G1 cyclin-dependent kinases. Genes Dev 9: 1149-1163, 1995.

18. Torii S, Yamamoto T, Tsuchiya Y and Nishida E: ERK MAP kinase in $\mathrm{G}$ cell cycle progression and cancer. Cancer Sci 97: 697-702, 2006.

19. Zhang M, Li J, Wang L, Tian Z, Zhang P, Xu Q, Zhang C, Wei F and Chen W: Prognostic significance of p21, p27 and survivin protein expression in patients with oral squamous cell carcinoma. Oncol Lett 6: 381-386, 2013.

20. Chiang KC, Yeh CN, Hsu JT, Chen LW, Kuo SF, Sun CC, Huang CC, Pang JH, Flanagan JN, Takano M, et al: MART-10, a novel vitamin $\mathrm{D}$ analog, inhibits head and neck squamous carcinoma cells growth through cell cycle arrest at G0/G1 with upregulation of p21 and p27 and downregulation of telomerase. J Steroid Biochem Mol Biol 138: 427-434, 2013.

21. Ling Y, Zhang C, Shen R, Xu Y, Zhu C, Lu M, Liu Y and Zhang C: p14ARF repression induced by promoter methylation associated with metastasis in esophageal squamous cell carcinoma. Dis Esophagus 27: 182-187, 2014.

22. Reed JA, Bales E, Xu W, Okan NA, Bandyopadhyay D and Medrano EE: Cytoplasmic localization of the oncogenic protein Ski in human cutaneous melanomas in vivo: Functional implications for transforming growth factor beta signaling. Cancer Res 61: 8074-8078, 2001.

23. Reed JA, Lin Q, Chen D, Mian IS and Medrano EE: SKI pathways inducing progression of human melanoma. Cancer Metastasis Rev 24: 265-272, 2005.

24. Akkiprik M, Hu L, Sahin A, Hao X and Zhang W: The subcellular localization of IGFBP5 affects its cell growth and migration functions in breast cancer. BMC Cancer 9: 103, 2009.

25. Thang ND, Nghia PT, Kumasaka MY, Yajima I and Kato M: Treatment of vemurafenib-resistant SKMEL-28 melanoma cells with paclitaxel. Asian Pac J Cancer Prev 16: 699-705, 2015. 
26. Juszczynski P, Kutok JL, Li C, Mitra J, Aguiar RC and Shipp MA BAL1 and BBAP are regulated by a gamma interferon-responsive bidirectional promoter and are overexpressed in diffuse large B-cell lymphomas with a prominent inflammatory infiltrate. Mol Cell Biol 26: 5348-5359, 2006.

27. Yan Q, Xu R, Zhu L, Cheng X, Wang Z, Manis J and Shipp MA: BAL1 and Its Partner E3 ligase, BBAP, link Poly (ADP-Ribose) activation, ubiquitylation, and double-strand DNA repair independent of ATM, MDC1, and RNF8. Mol Cell Biol 33: 845-857, 2013.

28. Johnson DP, Spitz GS, Tharkar S, Quayle SN, Shearstone JR, Jones S, McDowell ME, Wellman H, Tyler JK, Cairns BR, et al: HDAC1,2 inhibition impairs EZH2- and BBAP- mediated DNA repair to overcome chemoresistance in EZH2 gain-of-function mutant diffuse large B-cell lymphoma. Oncotarget 6: 4863-4887, 2015.

29. Bachmann SB, Frommel SC, Camicia R, Winkler HC, Santoro R and Hassa PO: DTX3L and ARTD9 inhibit IRF1 expression and mediate in cooperation with ARTD8 survival and proliferation of metastatic prostate cancer cells. Mol Cancer 13: 125, 2014

30. Zhang $\mathrm{L}$ and Zou W: Inhibition of integrin $\beta 1$ decreases the malignancy of ovarian cancer cells and potentiates anticancer therapy via the FAK/STAT1 signaling pathway. Mol Med Rep 12: 7869-7876, 2015.

31. Zhang L, Wang D, Jiang W, Edwards D, Qiu W, Barroilhet LM, Rho JH, Jin L, Seethappan V, Vitonis A, et al: Activated networking of platelet activating factor receptor and FAK/STAT1 induces malignant potential in BRCA1-mutant at-risk ovarian epithelium. Reprod Biol Endocrinol 8: 74, 2010.

32. Lee MH, Kachroo P, Pagano PC, Yanagawa J, Wang G, Walser TC, Krysan K, Sharma S, John MS, Dubinett SM and Lee JM: Combination treatment with Apricoxib and IL-27 enhances inhibition of epithelial-mesenchymal transition in human lung cancer cells through a STAT1 dominant pathway. J Cancer Sci Ther 6: 468-477, 2014.

33. Kachroo P, Lee MH, Zhang L, Baratelli F, Lee G, Srivastava MK, Wang G, Walser TC, Krysan K, Sharma S, et al: IL-27 inhibits epithelial-mesenchymal transition and angiogenic factor production in a STAT1-dominant pathway in human non-small cell lung cancer. J Exp Clin Cancer Res 32: 97, 2013.
34. Zhang Y, Zhang Y, Yun H, Lai R and Su M: Correlation of STAT1 with apoptosis and cell-cycle markers in esophageal squamous cell carcinoma. PLoS One 9: e113928, 2014.

35. Sun Y, Yang S, Sun N and Chen J: Differential expression of STAT1 and p21 proteins predicts pancreatic cancer progression and prognosis. Pancreas 43: 619-623, 2014.

36. Liu W, Dong M, Bo L, Li C, Liu Q, Li Z and Jin F: Epigallocatechin-3-gallate suppresses alveolar epithelial cell apoptosis in seawater aspiration-induced acute lung injury via inhibiting STAT1-caspase-3/p21 associated pathway. Mol Med Rep 13: 829-836, 2016.

37. Li W, Fan J, Banerjee D and Bertino JR: Overexpression of p21(waf1) decreases G2-M arrest and apoptosis induced by paclitaxel in human sarcoma cells lacking both p53 and functional Rb protein. Mol Pharmacol 55: 1088-1093, 1999.

38. Héliez C, Baricault L, Barboule $N$ and Valette A: Paclitaxel increases p21 synthesis and accumulation of its AKT-phosphorylated form in the cytoplasm of cancer cells. Oncogene 22: 3260-3268, 2003.

39. Ferreira P, Oliveira MJ, Beraldi E, Mateus AR, Nakajima T, Gleave M, Yokota J, Carneiro F, Huntsman D, Seruca R and Suriano G, Loss of functional E-cadherin renders cells more resistant to the apoptotic agent taxol in vitro. Exp Cell Res 310: 99-104, 2005

40. Kang Y, Hu W, Ivan C, Dalton HJ, Miyake T, Pecot CV, Zand B, Liu T, Huang J, Jennings NB, et al: Role of focal adhesion kinase in regulating YB-1-mediated paclitaxel resistance in ovarian cancer. J Natl Cancer Inst 105: 1485-1495, 2013.

41. Smalley KS: PLX-4032, a small-molecule B-Raf inhibitor for the potential treatment of malignant melanoma. Curr Opin Investig Drugs 11: 699-706, 2010.

42. Flaherty KT, Puzanov I, Kim KB, Ribas A, McArthur GA, Sosman JA, O'Dwyer PJ, Lee RJ, Grippo JF, Nolop K and Chapman PB: Inhibition of mutated, activated BRAF in metastatic melanoma. N Engl J Med 363: 809-819, 2010.

43. Bollag G, Tsai J, Zhang J, Zhang C, Ibrahim P, Nolop K and Hirth P: Vemurafenib: The first drug approved for BRAF-mutant cancer. Nat Rev Drug Discov 11: 873-886, 2012.

44. Nazarian R, Shi H, Wang Q, Kong X, Koya RC, Lee H, Chen Z, Lee MK, Attar N, Sazegar H, et al: Melanomas acquire resistance to B-RAF(V600E) inhibition by RTK or N-RAS upregulation. Nature 468: 973-977, 2010. 